\title{
Pulsed polarization on Au|YSZ NOx-sensors with and without catalytic layer
}

\author{
Nils Donker ${ }^{1}$, Anastasiya Ruchets², Daniela Schönauer-Kamin ${ }^{1}$, \\ Jens Zosel2, Ulrich Guth ${ }^{3}$, Ralf Moos ${ }^{1}$ \\ ${ }^{1}$ Department of Functional Materials, University of Bayreuth, 95440 Bayreuth, Germany \\ ${ }^{2}$ Kurt-Schwabe-Institut für Mess- und Sensortechnik Meinsberg e.V., 04736 Waldheim, Germany \\ ${ }^{3}$ Dresden University of Technology, Department of Chemistry and Food Chemistry, Dresden, Germany \\ funktionsmaterialien@uni-bayreuth.de
}

\section{Summary:}

Sensors of the type Au|YSZ|Au were produced, and some of them were covered with an additional Pt containing catalyst layer. These sensors were operated in the pulsed polarization mode. Their sensitivity to $\mathrm{NO}_{x}$ was investigated. The pure gold sensor showed almost no NO signal, but a clear signal towards $\mathrm{NO}_{2}$. The catalyst-coated sensor responded to both gases, $\mathrm{NO}$ and $\mathrm{NO}_{2}$. Therefore, we assume that $\mathrm{NO}_{2}$ is essential for the sensor effect, which could not have been explicitly shown in previous studies.

Keywords: pulsed polarization, Au | YSZ, NOx detection, exhaust gas sensor, dynamic method

\section{Motivation}

Gaseous components from combustion processes are among the main pollutants in our environment. Therefore, it is important to measure them for continuous optimization of the combustion process. Newer approaches for the detection of such gases are directed towards dynamic instead of static methods. This is expected to lead to further improvements in selectivity. Examples for such methods are cyclovoltammetry [1], thermocyclic operation [2] or pulsed polarization [3]. In the latter case, nitrogen oxides could be detected selectively, but the exact mechanism is still unclear. In this method, catalytically active Pt-electrodes are polarized at $400{ }^{\circ} \mathrm{C}$ and the subsequent self-discharge behavior is evaluated. It is expected that $\mathrm{NO}$ and $\mathrm{NO}_{2}$ are present in thermodynamic equilibrium at the electrode, independent of the actual concentrations [4]. In this work, the influences of the $\mathrm{NO} / \mathrm{NO}_{2}-$ equilibrium on the sensor signal will be investigated in more detail.

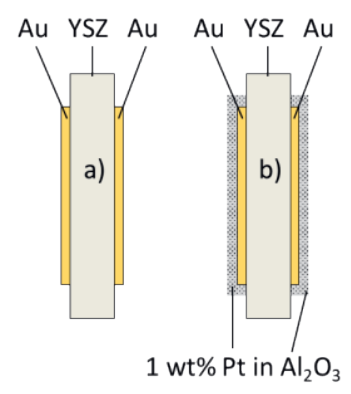

Fig.1. Schematic view of the sensors a) without and b) with catalytic layer

\section{Experimental}

The here-used sensors consist of screen-printed Au-electrodes (area $=5 \times 5 \mathrm{~mm}^{2}$ ) that are applied to both sides of an 8YSZ substrate and fired at $850^{\circ} \mathrm{C}$ (see Fig. 1). A catalytic layer was then added to some of the electrodes. It consists of $1 \mathrm{wt} \% \mathrm{Pt}$ added to porous $\mathrm{Al}_{2} \mathrm{O}_{3}$. These catalytic layers were fired at $700{ }^{\circ} \mathrm{C}$, whereby the sensors without catalytic layer were also fired in order to avoid influences by the firing process.

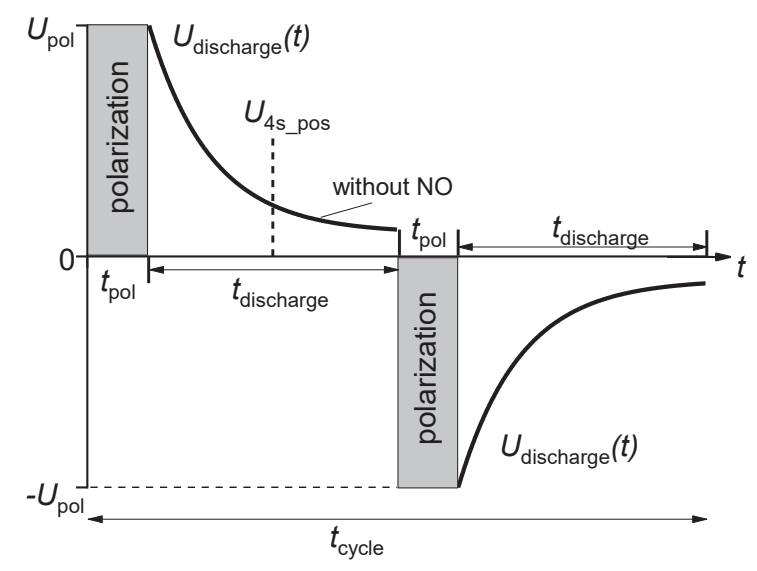

Fig. 2. Overview of a pulsed polarization cycle

Then, the sensors were operated by pulsed polarization. For this purpose, the sensor was polarized for a polarization duration $t_{\mathrm{pol}}=1 \mathrm{~s}$ with $\mathrm{a}$ polarization voltage $U_{\mathrm{pol}}=1 \mathrm{~V}$. Afterwards the self-discharge was measured as an open circuit potential, OCP, for $t_{\text {discharge }}=10 \mathrm{~s}$. These polarization and self-discharge phases were repeated continuously, always polarizing with alternating 
polarity. To generate a sensor signal from these cycles, the discharge voltage is evaluated at a fixed point in time in the cycle, for example $4 \mathrm{~s}$ after positive polarization $U_{4 \text { s_pos }}$ (Fig. 2).

A mixture containing $10 \% \mathrm{O}_{2}$ and $2 \% \mathrm{H}_{2} \mathrm{O}$ in $\mathrm{N}_{2}$ was used as base gas. Additionally, 50-400 ppm $\mathrm{NO}$ and $\mathrm{NO}_{2}$ were added stepwise. All measurements were performed at $400{ }^{\circ} \mathrm{C}$ in a tube furnace.

\section{Results}

The results of two measurements of Au|YSZ|Au are shown in Fig. 3. Fig 3a shows the discharge voltages of an Au-sensor without catalyst layer $1 \mathrm{~s}$ and $9 \mathrm{~s}$ after positive polarization. It can be seen that this sensor almost does not respond to NO. Thus, on the $1 \mathrm{~s}$ curve almost no NO influence is visible. After $9 \mathrm{~s}$ a slight change to more positive voltages can be seen, which means a slowing down of the self-discharge. With added $\mathrm{NO}_{2}$, however, clear change to more negative voltages can be seen. This indicates an accelerated self-discharge. These $\mathrm{NO}_{2}$ signals are visible after $1 \mathrm{~s}$ as well as after $9 \mathrm{~s}$ and show a similar effect as observed for sensors with Pt-electrodes [3].
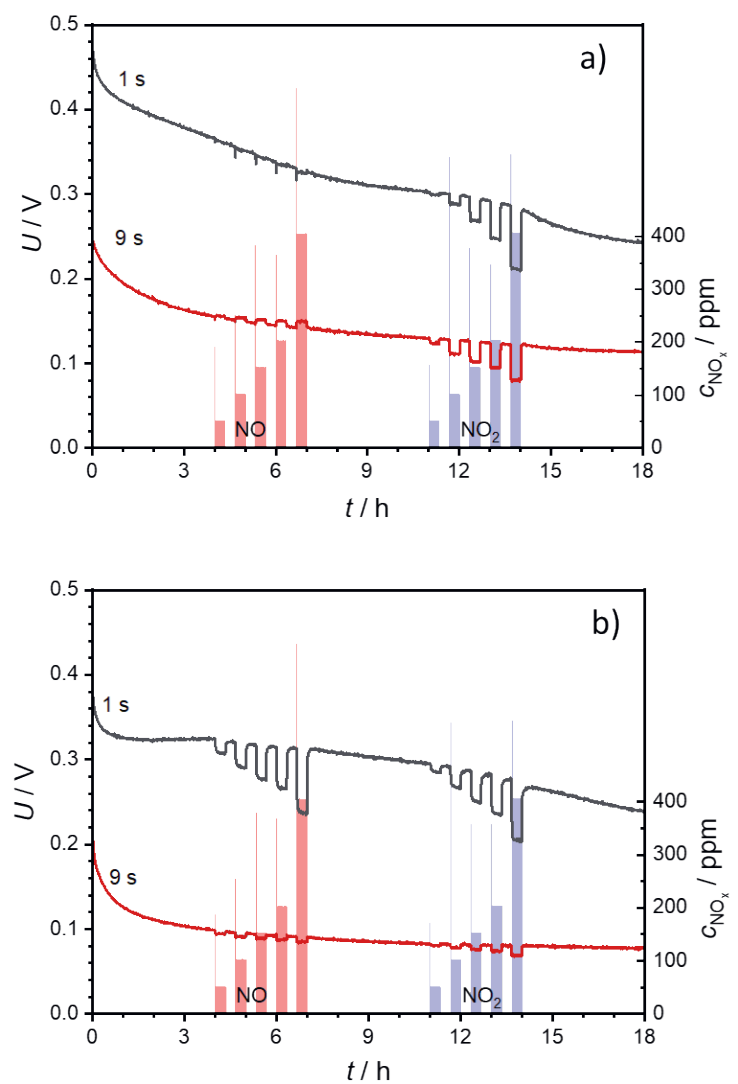

Fig. 3. Depolarization voltages after 1 and $9 \mathrm{~s}$ after positive polarization at Au|YSZ|Au sensors a) without and b) with additional catalytic layer on both electrodes.
Fig. 3b shows the discharge curves of a sensor with a catalytic layer on top of both gold electrodes. Here, a clear signal for $\mathrm{NO}$ as well as for $\mathrm{NO}_{2}$ can be seen. This is particularly pronounced $1 \mathrm{~s}$ after polarization. Here, the effects of $\mathrm{NO}$ and $\mathrm{NO}_{2}$ hardly differ.

\section{Discussion}

These results show that an $\mathrm{Au}$ sensor without catalyst hardly responds to NO but clearly responds to $\mathrm{NO}_{2}$. Only with a catalytic layer, which oxidizes a part of the $\mathrm{NO}$ to $\mathrm{NO}_{2}$ due to the thermodynamic equilibrium, NO becomes measurable. Since the electrodes of Pt sensors are catalytically active themselves, they may also react primarily to $\mathrm{NO}_{2}$, which is formed by oxidation of NO directly at the electrode.

\section{Conclusion}

It could be shown that $\mathrm{NO}_{2}$ in contrast to $\mathrm{NO}$ at $400{ }^{\circ} \mathrm{C}$ has a direct influence on the self-discharge of the sensor. In order to further investigate this effect, measurements with single-sided catalytic coated electrodes as well as measurements at other temperatures will be performed.

\section{References}

[1] A. Ruchets, N. Donker, D. Schönauer-Kamin, R. Moos, J. Zosel, U. Guth, M. Mertig, Selectivity improvement towards hydrogen and oxygen of solid electrolyte sensors by dynamic electrochemical methods, Sens. Actuators B 290 (2019) 53-58.

[2] X. Zhang, H. Kohler, M. Schwotzer, U. Guth, Mixed-potential gas sensor with PtAu-8YSZ sensing electrode: Electric potential difference measurements at isothermal and thermo-cyclic operation, Sens. Actuators B 217 (2015) 107112.

[3] N. Donker, A. Ruchets, D. Schönauer-Kamin, J. Zosel, U. Guth, R. Moos, Influence of Pt paste and the firing temperature of screen-printed electrodes on the NO detection by pulsed polarization, J. Sens. Sens. Syst. 9 (2020) 293300.

[4] T. Ritter, J. Lattus, G. Hagen, R. Moos, On the influence of the $\mathrm{NO}_{x}$ equilibrium reaction on mixed potential sensor signals: A comparison between FE modelling and experimental data, Sens. Actuators B 296 (2019) 126627.

\section{Acknowledgement}

We thank the German Research Foundation (DFG) for financial support under grants $\mathrm{MO}$ 1060/30-1 and ZO 139/3-1 